Article

\title{
Theoretical Investigations of the Photophysical Properties of Star-Shaped $\pi$-Conjugated Molecules with Triarylboron Unit for Organic Light-Emitting Diodes Applications
}

\author{
Ruifa Jin ${ }^{1,2, *}$, Xiaofei Zhang ${ }^{1,2}$, Wenmin Xiao ${ }^{1,2}$ and Dongmei Luo ${ }^{1,2}$ \\ 1 College of Chemistry and Chemical Engineering, Chifeng University, Chifeng 024000, China; \\ 15849630086@126.com (X.Z.); xiaowenmin6868@163.com (W.X.); luodongmei1976@163.com (D.L.) \\ 2 Inner Mongolia Key Laboratory of Photoelectric Functional Materials, Chifeng University, \\ Chifeng 024000, China \\ * Correspondence: Ruifajin@163.com; Tel./Fax: +86-0476-8300-370
}

Received: 15 September 2017; Accepted: 17 October 2017; Published: 18 October 2017

\begin{abstract}
The density functional theory (DFT) and time-dependent DFT (TD-DFT) methodologies have been applied to explore on a series of star-shaped $\pi$-conjugated organoboron systems for organic light-emitting diode (OLED) materials. The compounds under investigation consist of benzene as $\pi$-bridge and different core units and triarylboron end groups. Their geometry structures, frontier molecular orbital (FMO) energies, absorption and fluorescence spectra, and charge transport properties have been investigated systematically. It turned out that the FMO energy levels, the band gaps, and reorganization energies optical are affected by the introduction of different core units and triarylboron end groups. The results suggest that the designed compounds are expected to be promising candidates for luminescent materials. Furthermore, they can also serve as hole and/or electron transport materials for OLEDs.
\end{abstract}

Keywords: organoborons molecules; electronic and optical properties; charge transport property; organic light-emitting diodes (OLEDs)

\section{Introduction}

Organic $\pi$-conjugated luminophors have recently stirred great attention because of their potential applications as molecular probes and switches, organic light-emitting diodes (OLEDs), and solid-state light sources [1-7]. Particularly, $\pi$-conjugated organoboron systems have attracted considerable interest for OLEDs due to their outstanding properties, such as their high photo and chemical stability, good charge transport property, and high fluorescence quantum yields [8-10]. Unfortunately, the efficiency of OLEDs is still comparatively low, a shortcoming that restricts their commercialization application. To promote the efficiency of OLEDs, the luminescence and charge transport properties have become the two top-priority issues for OLEDs materials [11]. It has therefore become an urgent need to find novel materials with high luminous efficiency and carrier mobility for use in OLEDs [12,13]. Since the vacant $\mathrm{p}_{\pi}$ orbital of boron and the extended $\pi$-system, the $\pi$-conjugated three-coordinate organoborons exhibited strong electron accepting ability [14] and good charge transport properties [15]. In addition, variations in the chromophore part of the molecule would influence the frontier molecular orbital (FMO) energy levels and thereby the color of emission [16,17]. Namely, the FMO energy levels and the color of emission can be modulated by the introduction of different groups in the molecules. Particularly, the introduction of an electron-donating group can improve the intense luminescence and carrier mobility. Therefore, $\pi$-conjugated organoboron systems are expected to be the promising candidates for bifunctional OLEDs materials with strong fluorescence and high carrier 
mobility $[18,19]$. Moreover, comparing with a linear one, $\pi$-conjugated materials with star-shaped architecture possess the prime virtues of their good charge transport property. This kind material can enhance the $\pi-\pi$ stacking of conjugated arms because of their high structural symmetry and planarity. Furthermore, they can also cause no an ordered, long-range, and coplanar $\pi-\pi$ stacking due to their steric hindrance $[20,21]$. On the other hand, theoretical investigation also plays an essential role in the design and synthesis of materials. A number of studies demonstrate the interplay between theory and experiment, which is capable of providing useful insights into the understanding of the nature of molecules [21-23]. Recently, it has been reported that triarylboron-systems $\pi$-conjugated three-coordinate organoborons possessed excellent optical and charge transfer properties for use in OLEDs [14].

In this contribution, with the aim to enhance the electronic, optical, and charge transfer properties of materials, we have designed new $\pi$-conjugated three-coordinate organoborons with benzene $\pi$-bridge fragments (BBs), different core fragments ( $\mathrm{CFs}$ ), and triarylboron end groups (TBGs) (Scheme 1). The purpose of this kind molecular structure is to investigate the relationship between topologic structure and electronic, optical, and charge transfer properties, providing a demonstration for the rational design of a novel candidate for luminescent and charge transport materials for OLEDs. By applying density functional theory (DFT) and time-dependent DFT (TD-DFT) methodology, we calculated the FMO (HOMO and LUMO) energies ( $E_{\mathrm{HOMO}}$ and $\left.E_{\mathrm{LUMO}}\right)$, the HOMO-LUMO gaps $\left(E_{\mathrm{g}}\right)$, the absorption and fluorescence spectra, and the reorganization energies of designed molecules.

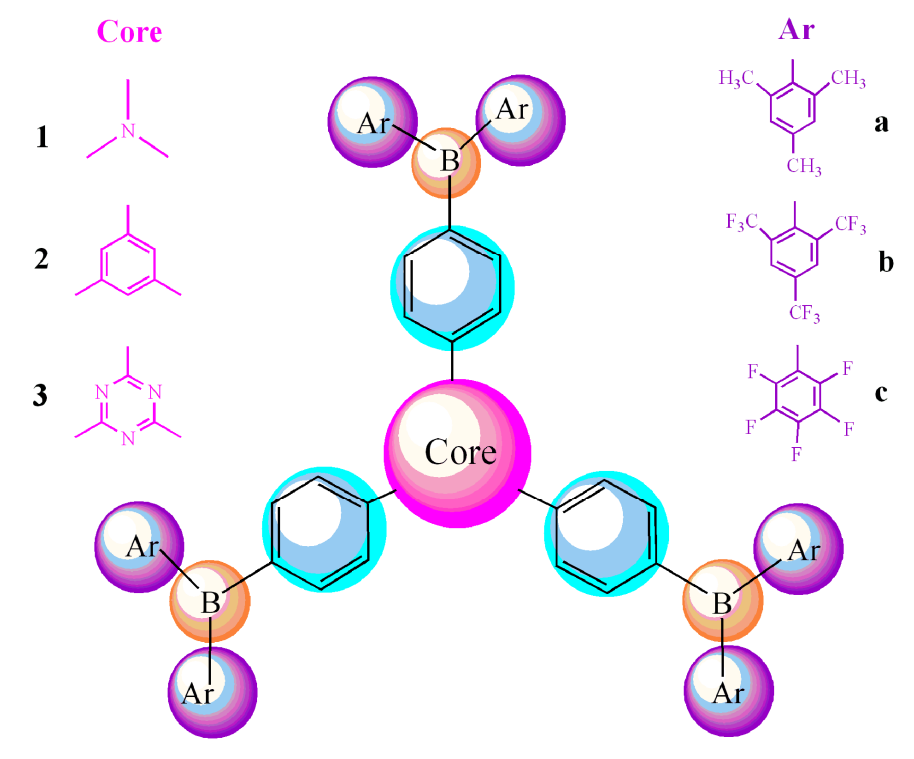

Scheme 1. Molecular structures of the investigated molecules.

\section{Results and Discussion}

\subsection{Frontier Molecular Orbitals}

With the aim to investigate the optical and electronic properties, the FMOs of the designed molecules were examined. The distributions HOMOs and LUMOs of the designed molecules are shown in Figure 1. The $E_{\mathrm{HOMO}}$ and $E_{\mathrm{LUMO}}, E_{\mathrm{g}}$, and the contributions of individual fragments (in \%) to the FMOs of the designed molecules are given in Table 1. From Figure 1, one can see that both HOMOs and LUMOs exhibit $\pi$ characteristics. For $\mathbf{1 a}-\mathbf{c}, \mathbf{2} \mathbf{b}, \mathbf{2} \mathbf{c}$, and $\mathbf{3} \mathbf{b}$, both the HOMOs and LUMOs are spread over the CFs, BBs, and TBGs of the molecules. However, the HOMOs are mainly localized on TBGs, while their LUMOs are spread over the whole molecule for $\mathbf{2 a}, \mathbf{3 a}$, and $\mathbf{3 c}$. Inspection of Table 1 reveals clearly that the HOMOs of $\mathbf{1 a}-\mathbf{c}, \mathbf{2} \mathbf{b}, \mathbf{2} \mathbf{c}$, and $\mathbf{3 b}$ are mainly localized on CFs and BBs, with minor contributions from the TBGs. Their LUMOs are mainly centralized on BBs and TBGs, 
with minimal density on CFs. The sum contributions of CFs and BBs for HOMOs are larger than $87.6 \%$, while the contributions of TBGs are within $15.7 \%$. For $\mathbf{2 a}, \mathbf{3 a}$, and $\mathbf{3} \mathbf{c}$, the contributions of TBGs for HOMOs are larger than $90.7 \%$, while the sum contributions of CFs and BBs are within $9.3 \%$. On the other hand, the sum contributions of BBs and TBGs of LUMOs are larger than $84.3 \%$, while the contributions of $\mathrm{CFs}$ are within $12.4 \%$. These results reveal that different configurations of the $\mathrm{CF}$ and TBG building blocks have obvious effects on the distribution of FMOs. Furthermore, the contributions of CFs and BBs for $\mathbf{1 a}, \mathbf{1} \mathbf{c}, \mathbf{2} \mathbf{b}, \mathbf{2 c}$, and $\mathbf{3 b}$ are decreased, while the corresponding contributions of TBGs are increased compared with those of HOMOs, respectively. The percentages of charge transfer from CFs and BBs to TBGs are 43.2, 53.9, 73.1, 53.0, and 55.2\%, respectively. In contrast, the contributions of CFs and BBs for $\mathbf{2 a}, \mathbf{3 a}$, and $\mathbf{3 c}$ are increased, while the corresponding contributions of TBGs are decreased compared with those of HOMOs. The corresponding charge transfer from TBGs to CFs and BBs are $38.3,65.5$, and $52.7 \%$, respectively. For $\mathbf{1 b}$, the contribution of CFs is decreased, and the contributions of BBs and TBGs are increased compared with those of HOMOs, respectively. These results reveal that the excitation of the electron from the HOMOs to the LUMOs causes the electronic density to flow mainly from CFs and BBs to TBGs for $\mathbf{1 a}, \mathbf{1} \mathbf{c}, \mathbf{2} \mathbf{b}, \mathbf{2 c}$, and $\mathbf{3 b}$. For $\mathbf{2 a}$, $\mathbf{3} \mathbf{a}$, and $\mathbf{3} \mathbf{c}$, the electronic densities mainly flow from TBG fragments to CFs and BBs. The electronic densities mainly flow from CFs to BBs and TBGs for $\mathbf{1 b}$. It suggests that $\mathrm{CFs}$ and BBs serve as donors and TBGs serve as acceptors for $\mathbf{1 a}, \mathbf{1} \mathbf{c}, \mathbf{2} \mathbf{b}, \mathbf{2 c}$, and $\mathbf{3 b}$. The CFs serve as the donor, and BBs and TBGs serve as acceptors for $\mathbf{1 b}$. In general, TBGs serve as electron acceptors. Interestingly, for $\mathbf{2 a}, \mathbf{3 a}$, and $\mathbf{3} \mathbf{c}$, the TBGs serve as donors, and CFs and BBs serve as acceptors. It is well known that the photophysical properties of intramolecular charge transfer are highly dependent on the electron donor/acceptor strength [24,25]. For $2 \mathbf{a}$ and $3 \mathbf{a}$, the reasons may be due to the electron donating of two mesitylene groups in TBGs, which strengthens the electron donating abilities of (Mes) ${ }_{2} \mathrm{~B}$ compared with those of CFs and BBs, respectively. For 3c, the TBGs serve as donors because of the strongly mesomeric effect of fluorine atoms of two pentafluorobenzenes groups in TBGs, which increases the electron donating ability of $(\mathrm{PFB})_{2} \mathrm{~B}$ compared with those of CFs and BBs.

Table 1. The FMO energies $E_{\mathrm{HOMO}}$ and $E_{\mathrm{LUMO}}, E_{\mathrm{g}}(\mathrm{eV})$, and $\mathrm{HOMO}$ and LUMO contributions (\%) of the designed molecules.

\begin{tabular}{|c|c|c|c|c|c|c|c|c|c|}
\hline \multirow{2}{*}{ Species } & \multicolumn{4}{|c|}{ HOMO } & \multicolumn{4}{|c|}{ LUMO } & \multirow{2}{*}{$E_{\mathrm{g}}$} \\
\hline & $E_{\text {Номо }}$ & $\mathrm{CF}^{\mathrm{a}}$ & $\mathbf{B B}^{\mathrm{b}}$ & TBG $^{c}$ & $E_{\text {LUMO }}$ & $\mathrm{CF}^{\mathrm{a}}$ & $\mathbf{B B}^{\mathbf{b}}$ & TBG $^{c}$ & \\
\hline $1 \mathrm{a}$ & -5.483 & 23.1 & 64.4 & 12.5 & -1.693 & 0.4 & 43.8 & 55.7 & 3.789 \\
\hline $1 b$ & -6.055 & 23.7 & 68.6 & 7.6 & -2.838 & 0.2 & 76.3 & 23.5 & 3.217 \\
\hline 1c & -6.270 & 23.1 & 64.5 & 12.4 & -2.806 & 0.3 & 33.4 & 66.3 & 3.464 \\
\hline $2 a$ & -6.244 & 2.3 & 7.1 & 90.7 & -1.754 & 14.3 & 33.3 & 52.4 & 4.490 \\
\hline $2 b$ & -6.842 & 46.9 & 47.3 & 5.9 & -2.794 & 4.3 & 16.7 & 79.0 & 4.049 \\
\hline $2 c$ & -7.006 & 45.0 & 43.8 & 11.2 & -2.736 & 9.0 & 26.8 & 64.2 & 4.270 \\
\hline $3 a$ & -6.279 & 0.1 & 4.6 & 95.3 & -2.215 & 34.6 & 35.6 & 29.8 & 4.064 \\
\hline $3 b$ & -7.440 & 18.7 & 74.1 & 7.2 & -3.011 & 15.7 & 21.9 & 62.4 & 4.429 \\
\hline $3 c$ & -7.395 & 0.0 & 0.2 & 99.8 & -3.066 & 23.1 & 29.8 & 47.1 & 4.328 \\
\hline
\end{tabular}

It is commonly known that the $E_{\mathrm{HOMO}}, E_{\mathrm{LUMO}}$, and $E_{\mathrm{g}}$ are closely related to the optical and electronic properties of molecules. For the designed molecules with nitrogen as core, 1a-c, the $E_{\mathrm{HOMO}}$ and $E_{\mathrm{LUMO}}$ are in the order $\mathbf{1 a}>\mathbf{1} \mathbf{b}>\mathbf{1} \mathbf{c}$ and $\mathbf{1 a}>\mathbf{1} \mathbf{c}>\mathbf{1} \mathbf{b}$, respectively. Therefore, the $E_{\mathrm{g}}$ values is in the sequence $\mathbf{1 a}>\mathbf{1} \mathbf{c}>\mathbf{1} \mathbf{b}$. This shows that Molecule 1a with ((mesitylene) ${ }_{2} \mathrm{~B}$, (Mes) $\left.{ }_{2} \mathrm{~B}\right) \mathrm{TBGs}$ possesses higher $E_{\mathrm{HOMO}}$ and $E_{\mathrm{LUMO}}$ and larger $E_{\mathrm{g}}$ in comparison to molecules with $\left.\left((1,3,5 \text {-tris(trifluoromethyl)benzene })_{2} \mathrm{~B} \text {, (FMes }\right)_{2} \mathrm{~B}\right)$, or $\left((1,2,3,4,5 \text {-pentafluorobenzene })_{2} \mathrm{~B},(\mathrm{PFB})_{2} \mathrm{~B}\right)$ as TBGs. The reason is that $-\mathrm{CF}_{3}$ and $-\mathrm{F}$ in TBGs (FMes) $)_{2} \mathrm{~B}$ and $(\mathrm{PFB})_{2} \mathrm{~B}$ is electron-withdrawing in nature, while $-\mathrm{CH}_{3}$ in TBG (Mes) $)_{2} \mathrm{~B}$ exhibit an electron-donating character. The electron-withdrawing groups $-\mathrm{CF}_{3}$ and $-\mathrm{F}$ are enable the electronic density to flow from donors to acceptors, while the 
electron-donating group $-\mathrm{CH}_{3}$ in TBG (Mes) ${ }_{2} \mathrm{~B}$ is unfavorable to the charge transfer. Moreover, the mesomeric effect of $-\mathrm{F}$ in $(\mathrm{PFB})_{2} \mathrm{~B}$ strengthens the electron donating ability of $(\mathrm{PFB})_{2} \mathrm{~B}$ in $\mathbf{1 c}$. Therefore, the electron-withdrawing strength of $(\mathrm{PFB})_{2} \mathrm{~B}$ is weaker than that of $(\mathrm{FMes})_{2} \mathrm{~B}$ in $\mathbf{1 b}$. As a consequence, the electronic density to flow from donors to acceptors for $\mathbf{1 b}$ is more fluent than that of $\mathbf{1 c}$. Thus, the $\mathrm{E}_{\mathrm{HOMO}}$ of $1 \mathrm{~b}$ is higher than that of $\mathbf{1} \mathbf{c}$, whereas the $\mathrm{E}_{\mathrm{LUMO}}$ of $\mathbf{1 b}$ is lower than that of 1c. Similar phenomena are found for the designed molecules with benzene as core, $\mathbf{2 a - c}$. For the designed molecules with 1,3,5-triazine as core, $\mathbf{3 a}-\mathbf{c}$, the sequences of $E_{\mathrm{HOMO}}$ and $E_{\mathrm{LUMO}}$ are $\mathbf{3 a}>\mathbf{3} \mathbf{c}>\mathbf{3} \mathbf{b}$ and $\mathbf{3 a}>\mathbf{3} \mathbf{b}>\mathbf{3} \mathbf{c}$, respectively. As a result, the order of $E_{\mathrm{g}}$ is $\mathbf{3 b}>\mathbf{3} \mathbf{c}>\mathbf{3 a}$. This shows that Molecule 3a with (Mes) ${ }_{2} \mathrm{~B}$ end group possesses higher $E_{\mathrm{LUMO}}$ and $E_{\mathrm{HOMO}}$ values and thus a smaller $E_{\mathrm{g}}$ in comparison with (FMes) $)_{2} \mathrm{~B}$ and $(\mathrm{PFB})_{2} \mathrm{~B}$ as the end group. These can be explained by the fact that the electron-donating group $-\mathrm{CH}_{3}$ in the (Mes) ${ }_{2} \mathrm{~B}$ end group of $3 \mathrm{a}$ improves charge transfer, while the electron-withdrawing group 1,3,5-triazine core fragment of $\mathbf{3 b}$ may prevent the electronic density from flowing from donor to acceptor fluently. These results indicate that the electron-withdrawing or electron-donating characters of CFs and TBGs significantly influence the $E_{\mathrm{g}}$ values for the designed molecules.

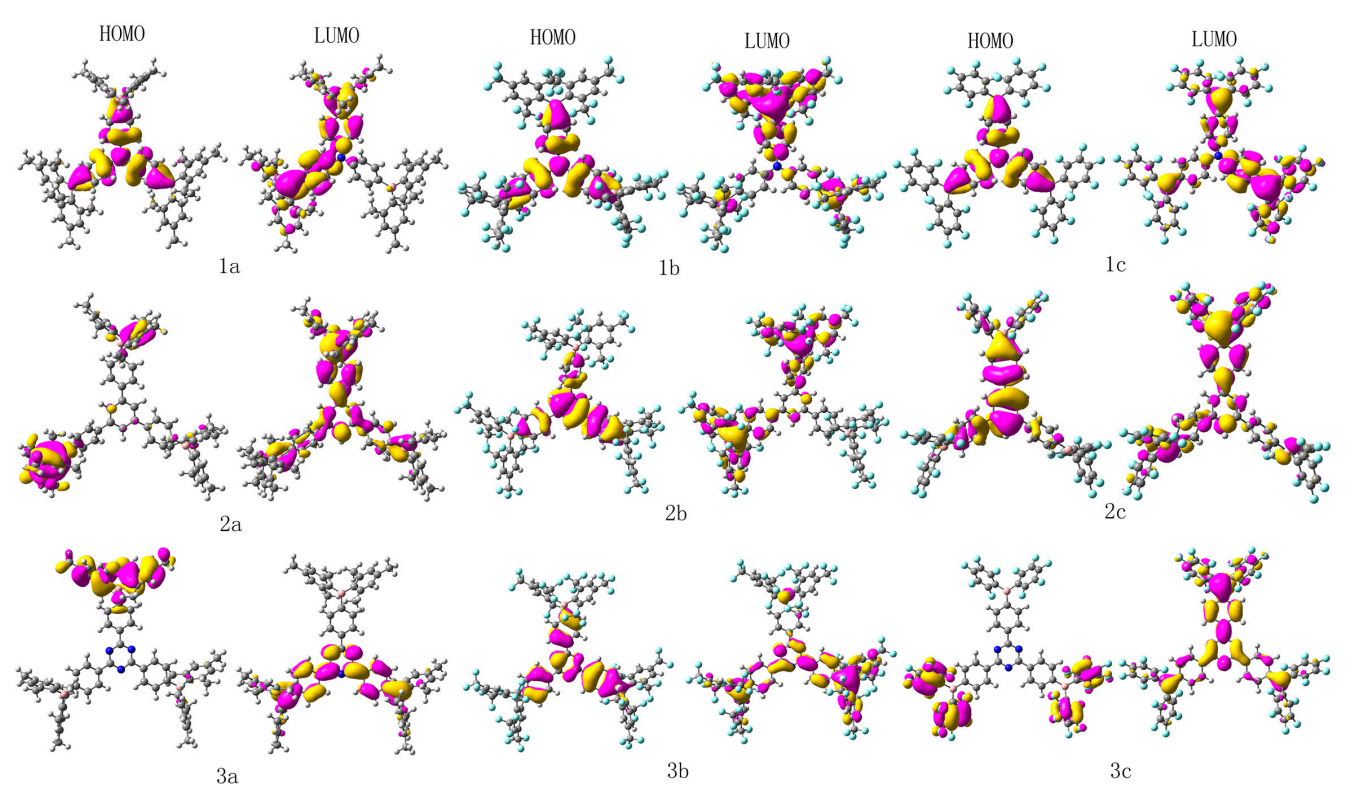

Figure 1. The electronic density contours of the frontier orbitals for the studied compounds at the PBE0/6-31G(d,p) level.

\subsection{Absorption and Fluorescence Spectra}

The longest absorption wavelengths $\lambda_{\mathrm{abs}}$, electronic transitions, main assignments, and the oscillator strength $f$ for the designed molecules are listed in Table 2. The absorptions of $\mathbf{1 a - c}, \mathbf{2 a}-\mathbf{c}$, and $\mathbf{3} \mathbf{b}$ are assigned to the $S_{0} \rightarrow S_{1}$ electronic transitions, while the absorption of $3 \mathbf{a}$ and $3 \mathbf{c}$ are assigned to the $\mathrm{S}_{0} \rightarrow \mathrm{S}_{2}$ and $\mathrm{S}_{0} \rightarrow \mathrm{S}_{3}$ electronic transitions, respectively. The longest absorption of $\mathbf{1 a}-\mathbf{c}, \mathbf{2} \mathbf{c}$, and $\mathbf{3 b}$ essentially mainly originates from HOMO $\rightarrow$ LUMO transition, while the corresponding absorption of $\mathbf{2} \mathbf{b}$ and $\mathbf{3} \mathbf{c}$ are mainly attributed to $\mathrm{HOMO} \rightarrow \mathrm{LUMO}+1$ transitions. However, the transitions of absorption for $\mathbf{2 a}$ and $3 \mathbf{a}$ correspond to $\mathrm{HOMO}-2 \rightarrow \mathrm{LUMO}+1$ transitions. Moreover, the sequence of $\lambda_{\mathrm{abs}}$ is $\mathbf{1 b}>\mathbf{1 c}>\mathbf{1 a}>\mathbf{3 a}>\mathbf{2 b}>\mathbf{2 a}>\mathbf{2 c}>\mathbf{3 c}>\mathbf{3 b}$. It indicates that the designed molecules with nitrogen as core show longer absorption wavelengths than those with benzene and 1,3,5-triazine as cores. Furthermore, $\mathbf{2} \mathbf{c}$ has the largest oscillator strengths in the designed molecules. $\mathbf{1 a}-\mathbf{c}, \mathbf{2} \mathbf{b}$, and $\mathbf{3 b}$ have large oscillator strengths, while the oscillator strengths of $\mathbf{2 a}, \mathbf{3} \mathbf{a}$, and $\mathbf{3} \mathbf{c}$ are smaller than those of other molecules. This indicates that $\mathbf{1} \mathbf{a}-\mathbf{c}, \mathbf{2} \mathbf{b}, \mathbf{2} \mathbf{c}$, and $\mathbf{3} \mathbf{b}$ may exhibit larger absorption intensity than those of $\mathbf{2 a}, \mathbf{3 a}$, and $\mathbf{3 c}$. 
Table 2. The longest of absorption wavelengths $\lambda_{\mathrm{abs}}$, the oscillator strength $f$, and assignments for the designed molecules at the TD-PBE0/6-31G(d,p)//PBE0/6-31G(d,p) level.

\begin{tabular}{ccccc}
\hline Species & Electronic Transitions & $\lambda_{\text {abs }}$ & $f$ & Assignment \\
\hline $\mathbf{1 a}$ & $\mathrm{S}_{0} \rightarrow \mathrm{S}_{1}$ & 399 & 0.68 & $\begin{array}{c}\text { HOMO } \rightarrow \text { LUMO (0.67) } \\
\text { HOMO } \rightarrow \text { LUMO+1 (0.17) }\end{array}$ \\
\hline $\mathbf{1 b}$ & $\mathrm{S}_{0} \rightarrow \mathrm{S}_{1}$ & 469 & 0.50 & $\begin{array}{c}\text { HOMO } \rightarrow \text { LUMO (0.70) } \\
\text { HOMO } \rightarrow \text { LUMO (0.69) }\end{array}$ \\
\hline $\mathbf{c}$ & $\mathrm{S}_{0} \rightarrow \mathrm{S}_{1}$ & 433 & 0.72 & $\begin{array}{c}\text { HOMO }-2 \rightarrow \text { LUMO (0.45) } \\
\text { HOMO }-1 \rightarrow \text { LUMO (0.33) }\end{array}$ \\
\hline $\mathbf{2 a}$ & $\mathrm{S}_{0} \rightarrow \mathrm{S}_{1}$ & 348 & 0.07 & $\begin{array}{c}\text { HOMO } \rightarrow \text { LUMO+1 (0.38) } \\
\text { HOMO } \rightarrow \text { LUMO+2 (0.45) }\end{array}$ \\
\hline $\mathbf{2 b}$ & $\mathrm{S}_{0} \rightarrow \mathrm{S}_{1}$ & 361 & 0.72 & $\begin{array}{c}\text { HOMO } \rightarrow \text { LUMO (0.38) } \\
\text { HOMO } \rightarrow \text { LUMO+1 (0.15) }\end{array}$ \\
\hline 3a & $\mathrm{S}_{0} \rightarrow \mathrm{S}_{1}$ & 344 & 1.14 & $\begin{array}{c}\text { HOMO }-2 \rightarrow \text { LUMO (0.38) } \\
\text { HOMO } \rightarrow \text { LUMO+1 (0.30) }\end{array}$ \\
\hline 3b & $\mathrm{S}_{0} \rightarrow \mathrm{S}_{2}$ & 374 & 0.07 & $\begin{array}{c}\text { HOMO } \rightarrow \text { LUMO (0.39) } \\
\text { HOMO }-1 \rightarrow \text { LUMO+1 (0.36) }\end{array}$ \\
\hline 3c & $\mathrm{S}_{0} \rightarrow \mathrm{S}_{1}$ & 335 & 0.88 & $\begin{array}{c}\text { HOMO } \rightarrow \text { LUMO+1 (0.48) } \\
\text { HOMO }-1 \rightarrow \text { LUMO+1 (0.23) }\end{array}$ \\
\hline
\end{tabular}

The longest fluorescence wavelengths $\lambda_{\mathrm{fl}}$, electronic transitions, main assignments, and the oscillator strength $f$ of the designed molecules are given in Table 3. The fluorescence of $\mathbf{1 a}, \mathbf{2} \mathbf{b}, \mathbf{3} \mathbf{a}$, and $\mathbf{3 b}$ are assigned to the $S_{1} \rightarrow S_{0}$ electronic transitions, while the fluorescence of $\mathbf{1 b}, \mathbf{1} \mathbf{c}, \mathbf{2} \mathbf{a}$, and $\mathbf{2 c}$ are assigned to the $S_{2} \rightarrow S_{0}$ electronic transitions. For $3 c$, the fluorescence is assigned to the $S_{3} \rightarrow S_{0}$ electronic transition. The LUMO $\rightarrow$ HOMO transitions play a dominant role for the fluorescence of $\mathbf{1 a}, \mathbf{2 a}, \mathbf{2 b}, \mathbf{3 a}$, and $\mathbf{3 b}$. However, the fluorescence's of $\mathbf{1 b}, \mathbf{1 c}$, and $\mathbf{2 c}$ are mainly attributed to LUMO $+1 \rightarrow$ HOMO transitions. For $3 \mathbf{c}$, the fluorescence is mainly attributed to a LUMO $\rightarrow$ HOMO -5 transition. Furthermore, $\mathbf{1 a}-\mathbf{c}, \mathbf{2} \mathbf{a}$, and $\mathbf{2 c}$ have larger oscillator strengths than those of $\mathbf{3 a}-\mathbf{c}$. The oscillator strength value of $\mathbf{2 b}$ is equal to that of $\mathbf{2 b}$. This implies that $\mathbf{1 a}-\mathbf{c}, \mathbf{2 a}$, and $\mathbf{2 c}$ exhibit fluorescence spectra that is stronger than those of $3 \mathbf{a}-\mathbf{c}$. This suggests that the designed molecules have greater fluorescence intensity and are promising luminescent materials for OLEDs, particularly for $1 \mathbf{a}-\mathbf{c}, \mathbf{2 a}$, and $\mathbf{2 c}$.

Table 3. The strongest fluorescence wavelengths $\lambda_{\mathrm{fl}}$, the oscillator strength $f$, and main assignments (coefficient) of the designed molecules at the TD-PBE0/6-31G(d,p)//TD-PBE0/6-31(d,p) level.

\begin{tabular}{|c|c|c|c|c|}
\hline Species & Electronic Transitions & $\lambda_{\mathrm{fl}}$ & $f$ & Assignment \\
\hline $1 \mathrm{a}$ & $\mathrm{S}_{1} \rightarrow \mathrm{S}_{0}$ & 456 & 0.25 & $\mathrm{LUMO} \rightarrow \mathrm{HOMO}(0.70)$ \\
\hline $1 \mathrm{~b}$ & $\mathrm{~S}_{2} \rightarrow \mathrm{S}_{0}$ & 496 & 0.49 & LUMO $+1 \rightarrow$ HOMO $(0.70)$ \\
\hline 1c & $\mathrm{S}_{2} \rightarrow \mathrm{S}_{0}$ & 499 & 0.57 & LUMO+1 $\rightarrow$ HOMO $(0.70)$ \\
\hline $2 a$ & $\mathrm{~S}_{2} \rightarrow \mathrm{S}_{0}$ & 364 & 0.41 & $\begin{array}{l}\mathrm{LUMO} \rightarrow \mathrm{HOMO}-1(0.70) \\
\mathrm{LUMO} \rightarrow \mathrm{HOMO}-3(0.20)\end{array}$ \\
\hline $2 b$ & $\mathrm{~S}_{1} \rightarrow \mathrm{S}_{0}$ & 613 & 0.03 & $\begin{array}{c}\text { LUMO } \rightarrow \text { HOMO }(0.69) \\
\text { LUMO } \rightarrow \text { HOMO-2 (0.10) }\end{array}$ \\
\hline $2 c$ & $\mathrm{~S}_{2} \rightarrow \mathrm{S}_{0}$ & 389 & 0.13 & LUMO $+1 \rightarrow$ HOMO $(0.70)$ \\
\hline $3 a$ & $\mathrm{~S}_{1} \rightarrow \mathrm{S}_{0}$ & 486 & 0.02 & $\begin{array}{c}\mathrm{LUMO} \rightarrow \mathrm{HOMO}(0.69) \\
\mathrm{LUMO}+2 \rightarrow \operatorname{HOMO}(0.13)\end{array}$ \\
\hline $3 b$ & $\mathrm{~S}_{1} \rightarrow \mathrm{S}_{0}$ & 528 & 0.03 & LUMO $\rightarrow$ HOMO $(0.70)$ \\
\hline $3 c$ & $\mathrm{~S}_{3} \rightarrow \mathrm{S}_{0}$ & 382 & 0.04 & $\begin{array}{c}\mathrm{LUMO} \rightarrow \mathrm{HOMO}-5(0.68) \\
\mathrm{LUMO}+2 \rightarrow \mathrm{HOMO}-5(0.14)\end{array}$ \\
\hline
\end{tabular}




\subsection{Reorganization Energy}

It is noteworthy that the small reorganization energy could be beneficial for a significant charge transport [26,27]. The reorganization energies for hole and electron of the designed molecules are calculated and listed in Table 4. Usually, $N, N^{\prime}$-diphenyl- $N, N^{\prime}$-bis(3-methlphenyl)-(1,1'-biphenyl)$4,4^{\prime}$-diamine (TPD) $\left(\lambda_{\mathrm{h}}=0.290 \mathrm{eV}\right)$ [28] and tris(8-hydroxyquinolinato)aluminum(III) (Alq3) $\left(\lambda_{\mathrm{e}}=0.276 \mathrm{eV}\right)[29]$ are the typical hole and electron transport materials, respectively. From Table 4, one can find that the $\lambda_{\mathrm{h}}$ values of $\mathbf{1 a}, \mathbf{1 c}, \mathbf{2 a}, \mathbf{2 c}$, and $\mathbf{3 a - c}$ are smaller than that of TPD. However, the $\lambda_{\mathrm{h}}$ values of $\mathbf{1 b}$ and $\mathbf{2} \mathbf{b}$ are larger than that of TPD. This indicates that the hole transfer rates of $\mathbf{1 a}$, $\mathbf{1 c}, \mathbf{2 a}, \mathbf{2 c}$, and $\mathbf{3 a - c}$ may be higher, while the corresponding hole transfer rates of $\mathbf{1 b}$ and $\mathbf{2 b}$ might be lower than that of TPD. On the other hand, the calculated $\lambda_{\mathrm{e}}$ values of the designed molecules $(0.082-0.263 \mathrm{eV})$ are smaller than that of Alq3. This suggests that the electron transfer rates of the designed molecules might be higher than that of Alq3. The $\lambda_{\mathrm{h}}$ values are predicted in the order $\mathbf{1 b}>\mathbf{1 a}>\mathbf{1 c}$ for 1a-c. The sequences of $\lambda_{\mathrm{h}}$ values are $\mathbf{2 b}>\mathbf{2 c}>\mathbf{2 a}$ and $3 \mathrm{~b}>3 \mathrm{c}>3 \mathrm{a}$ for $\mathbf{2 a - c}$ and $3 \mathrm{a}-\mathbf{c}$, respectively. This suggests that the (Mes) ${ }_{2} \mathrm{~B}$ and $(\mathrm{PFB})_{2} \mathrm{~B}$ end groups can increase the hole transfer rates, while the (FMes) ${ }_{2} B$ end groups decrease the hole transfer rates for the designed molecules. For the $\lambda_{\mathrm{e}}$, the order of $\mathbf{1 a}-\mathbf{c}$ and $\mathbf{2 a}-\mathbf{c}$ are $\mathbf{1 a}>\mathbf{1 b}>\mathbf{1 c}$ and $\mathbf{2 a}>\mathbf{2 b}>\mathbf{2 c}$, respectively, while the sequences of $3 \mathbf{a}-\mathbf{c}$ is $\mathbf{3 a}>\mathbf{3} \mathbf{c}>\mathbf{3} \mathbf{b}$. This implies that molecules with (FMes) ${ }_{2} \mathrm{~B}$ and $(\mathrm{PFB})_{2} \mathrm{~B}$ end groups have greater electron transfer rates than those with (Mes) ${ }_{2} B$ end groups, respectively. Therefore, 1a, 1c, 2a, 2c, and $3 \mathbf{a}-\mathbf{c}$ are expected to be promising candidates for hole as well as electron transport materials, whereas $\mathbf{1} \mathbf{b}$ and $\mathbf{2} \mathbf{b}$ can serve as electron transport materials only.

Table 4. The predicted $\lambda_{\mathrm{e}}$ and $\lambda_{\mathrm{h}}$ (both in $\mathrm{eV}$ ) of the designed molecules at the B3LYP/6-31G(d,p) level.

\begin{tabular}{ccc}
\hline Species & $\lambda_{\mathbf{h}}$ & $\lambda_{\mathbf{e}}$ \\
\hline $\mathbf{1 a}$ & 0.200 & 0.263 \\
$\mathbf{1 b}$ & 0.365 & 0.176 \\
$\mathbf{1 c}$ & 0.024 & 0.143 \\
$\mathbf{2 a}$ & 0.069 & 0.156 \\
$\mathbf{2 b}$ & 0.369 & 0.122 \\
$\mathbf{2 c}$ & 0.096 & 0.082 \\
3a & 0.073 & 0.273 \\
3b & 0.270 & 0.134 \\
3c & 0.109 & 0.190 \\
\hline
\end{tabular}

\section{Materials and Methods}

\section{Computational Methods}

All calculations were performed using Gaussian 09 code [30]. Geometry optimizations in the ground state $\left(\mathrm{S}_{0}\right)$ and the lowest singlet excited state $\left(\mathrm{S}_{1}\right)$ were carried out using the PBE0 and TD-PBE0 functionals, respectively, together with the 6-31G $(\mathrm{d}, \mathrm{p})$ basis set. On the basis of the optimized $S_{0}$ and $S_{1}$ geometries, the absorption and fluorescence spectra were predicted with the TD-PBE0/6-31G(d,p) method. With the aim to attest to the validity of the selected approach, $N$-(4-(dimesitylboryl)phenyl)- $N$-phenylbenzenamine (DBPB) was taken as an example because its geometric structure is similar to those of the designed molecules. The molecular structure of DBPB is presented in Figure S1. The geometry optimizations of DBPB in $S_{0}$ and $S_{1}$ states were carried out via the DFT and TD-DFT method using the 6-31G(d,p) basis set, respectively. The absorptions and fluorescence spectra were predicted using TD-DFT with the 6-31G $(\mathrm{d}, \mathrm{p})$ basis set based on the optimized geometries in $S_{0}$ and $S_{1}$ states, respectively. The various functionals for all DFT and TD-DFT computations include B3LYP, PBE0, CAM-B3LYP, wB97XD, and M062X. The longest absorptions and fluorescence wavelengths of DBPB are listed in Table S1. The results displayed in Table S1 show that the TD-PBE0/6-31G(d,p) method provided a better agreement with the reported experimental 
observations [14] than those obtained with other methods. Furthermore, our previous work [31] and other reports in the literature [32] suggest that PBE0 appeared notably adapted to organoboron compounds. Therefore, geometry optimizations, band gaps $E_{\mathrm{g}}$, and the absorption and fluorescence properties of the designed molecules were carried out with the PBE0/6-31G(d,p) method.

According to Marcus electron transfer theory [26,27], two key factors that determine the charge transfer rates are the charge transfer coupling integral $V$ and the reorganization energy $\lambda$. The $V$ values can be obtained through the crystal data. However, the crystal structures of the designed molecules are unavailable and may be non-crystal. Therefore, we investigate the charge transport property of the designed molecules using reorganization energies $\lambda$. The $\lambda$ can be partitioned into internal and external contributions. The internal reorganization energy $\lambda_{\text {int }}$ is induced by structural change between ionic and neutral states [33]. The external reorganization energy $\lambda_{\text {ext }}$ arises from the surrounding media in bulk materials. Generally, the predicted value of $\lambda_{\text {ext }}$ in pure organic phases is not only small but also much smaller than its $\lambda_{\text {int }}$ [34-36]. Therefore, we focus on the $\lambda_{\text {int }}$ exclusively. The $\lambda_{\mathrm{e}}$ and $\lambda_{\mathrm{h}}$ can be calculated with the following equations [37]:

$$
\begin{aligned}
& \lambda_{e}=\left(E_{0}^{-}-E_{-}^{-}\right)+\left(E_{-}^{0}-E_{0}^{0}\right) \\
& \lambda_{h}=\left(E_{+}^{-}-E_{+}^{+}\right)+\left(E_{+}^{0}-E_{0}^{0}\right)
\end{aligned}
$$

where $E_{+}^{0}$ and $E_{-}^{0}$ represent the energy of the neutral species with the optimized structure of the cation and anion species, while $E_{+}^{+}$and $E_{-}^{-}$are the energies of the cation and anion species with the optimized cation and anion structure, respectively. $E_{0}^{+}, E_{0}^{-}$, and $E_{0}^{0}$ are the energies of the cation, anion, and neutral species with the optimized neutral structure, respectively. Our results have thus been compared with results reported in the literature [36,37]. The $\lambda$ for electron $\left(\lambda_{\mathrm{e}}\right)$ and hole $\left(\lambda_{\mathrm{h}}\right)$ were predicted at the B3LYP/6-31G $(\mathrm{d}, \mathrm{p})$ level.

\section{Conclusions}

In the study, a series of star-shaped $\pi$-conjugated organoboron compounds have been designed and systematically investigated for OLED applications. By applying density functional theory (DFT) and time-dependent DFT (TD-DFT) methodology, we calculated the FMO (HOMO and LUMO) energies, the HOMO-LUMO gaps, the absorption and fluorescence spectra, and the reorganization energies of designed molecules. It turned out that the optical, electronic, and charge transport properties are affected by the core fragments and TBGs. Our results suggest that the designed molecules can serve as luminescent materials for OLEDs. In addition, they are expected to be promising candidates for hole and/or electron transport materials.

Supplementary Materials: Supplementary materials can be found at www.mdpi.com/1422-0067/18/10/2178/s1.

Acknowledgments: Financial supports from the NSFC (No. 21563002), the Natural Science Foundation of Inner Mongolia Autonomous Region (No. 2015MS0201), and the Research Program of Sciences at Universities of Inner Mongolia Autonomous Region (No. NJZZ235) are gratefully acknowledged.

Author Contributions: Ruifa Jin conceived and designed the calculations; Xiaofei Zhang contributed to the performance and analysis of the frontier molecular orbitals and absorption spectra; Wenmin Xiao performed the reorganization energies and transport properties; Dongmei Luo helped with results interpretation. Ruifa Jin wrote the paper.

Conflicts of Interest: The authors declare no conflict of interest. 


\section{Abbreviations}

\begin{tabular}{|c|c|}
\hline DFT & density function theory \\
\hline TD-DFT & time-dependent density function theory \\
\hline OLEDs & organic light-emitting diodes \\
\hline FMOs & frontier molecular orbital energies \\
\hline HOMO & highest occupied molecular orbital \\
\hline LUMO & lowest unoccupied molecular orbital \\
\hline BBs & benzene $\pi$-bridge fragments \\
\hline CFs & core fragments \\
\hline TBGs & triarylboron end groups \\
\hline$(\mathrm{Mes})_{2} \mathrm{~B}$ & (mesitylene) ${ }_{2} \mathrm{~B}$ \\
\hline$(\mathrm{FMes})_{2} \mathrm{~B}$ & 1,3,5-tris(trifluoromethyl)benzene) ${ }_{2} \mathrm{~B}$ \\
\hline$(\mathrm{PFB})_{2} \mathrm{~B}$ & 1,2,3,4,5-pentafluorobenzene) ${ }_{2} \mathrm{~B}$ \\
\hline DBPB & $N$-(4-(dimesitylboryl)phenyl)- $N$-phenylbenzenamine \\
\hline
\end{tabular}

\section{References}

1. Chi, Z.; Zhang, X.; Xu, B.; Zhou, X.; Ma, C.; Zhang, Y.; Liu, S.; Xu, J. Recent advances in organic mechanofluorochromic materials. Chem. Soc. Rev. 2012, 41, 3878-3896. [CrossRef] [PubMed]

2. Li, D.; Zhang, H.; Wang, Y. Four-coordinate organoboron compounds for organic light-emitting diodes (OLEDs). Chem. Soc. Rev. 2013, 42, 8416-8433. [CrossRef] [PubMed]

3. Shi, H.; Dai, J.; Xu, L.; Shi, L.; Fang, L.; Shuang, S.; Dong, C. A boron-containing carbazole dimer: Synthesis, photophysical properties and sensing properties. Org. Biomol. Chem. 2012, 10, 3852-3858. [CrossRef] [PubMed]

4. Steffen, A.; Tay, M.G.; Batsanov, A.S.; Howard, J.A.K.; Beeby, A.; Vuong, K.Q.; Sun, X.Z.; George, M.W.; Marder, T.B. 2,5-Bis(p-r-arylethynyl)rhodacyclopentadienes show intense fluorescence: Denying the presence of a heavy atom. Angew. Chem. Int. Ed. 2010, 49, 2349-2353. [CrossRef]

5. Jou, J.H.; Kumar, S.; Agrawal, A.; Li, T.H.; Sahoo, S. Approaches for fabricating high efficiency organic light emitting diodes. J. Mater. Chem. C 2015, 3, 2974-3002. [CrossRef]

6. Duan, L.; Qiao, J.; Sun, Y.; Qiu, Y. Strategies to design bipolar small molecules for OLEDs: Donor-acceptor structure and non-donor-acceptor structure. Adv. Mater. 2011, 23, 1137-1144. [CrossRef] [PubMed]

7. Kaji, H.; Suzuki, H.; Fukushima, T.; Shizu, K.; Suzuki, K.; Kubo, S.; Komino, T.; Oiwa, H.; Suzuki, F.; Wakamiya, A.; et al. Purely organic electroluminescent material realizing $100 \%$ conversion from electricity to light. Nat. Commun. 2015, 6, 8476. [CrossRef] [PubMed]

8. Kubota, Y.; Tsuzuki, T.; Funabiki, K.; Ebihara, M.; Matsui, M. Synthesis and fluorescence properties of a pyridomethene-BF 2 complex. Org. Lett. 2010, 12, 4010-4013. [CrossRef] [PubMed]

9. Hudson, Z.M.; Wang, S. Impact of donor-acceptor geometry and metal chelation on photophysical properties and applications of triarylboranes. Acc. Chem. Res. 2009, 42, 1584-1596. [CrossRef] [PubMed]

10. Yang, X.; Zhou, G.; Wong, W.Y. Functionalization of phosphorescent emitters and their host materials by main-group elements for phosphorescent organic light-emitting devices. Chem. Soc. Rev. 2015, 44, 8484-8575. [CrossRef] [PubMed]

11. Du, C.; Ye, S.; Liu, Y.; Guo, Y.; Wu, T.; Liu, H.; Zheng, J.; Cheng, C.; Zhuab, M.; Yua, G. Fused-seven-ring anthracene derivative with two sulfur bridges for high performance red organic light-emitting diodes. Chem. Commun. 2010, 46, 8573-8575. [CrossRef] [PubMed]

12. Slinker, J.; Bernards, D.; Houston, P.L.; Abruňa, H.D.; Bernhard, S.; Malliaras, G.G. Solid-state electroluminescent devices based on transition metal complexes. Chem. Commun. 2003, 19, 2392-2399. [CrossRef]

13. He, Z.; Wong, W.Y.; Yu, X.; Kwork, H.S.; Lin, Z. Phosphorescent platinum(II) complexes derived from multifunctional chromophores: Synthesis, structures, photophysics, and electroluminescence. Inorg. Chem. 2006, 45, 10922-10937. [CrossRef] [PubMed]

14. Zhang, Z.; Edkins, R.M.; Nitsch, J.; Fucke, K.; Steffen, A.; Longobardi, L.E.; Stephan, D.W.; Lambert, C.; Marder, T.B. Optical and electronic properties of air-stable organoboron compounds with strongly electron-accepting bis(fluoromesityl)boryl groups. Chem. Sci. 2015, 6, 308-321. [CrossRef] [PubMed] 
15. Kaim, W.; Hosmane, N.S.; Záliš, S.; Maguire, J.A.; Lipscomb, W.N. Boron atoms as spin carriers in two- and three-dimensional systems. Angew. Chem. Int. Ed. 2009, 48, 5082-5091. [CrossRef] [PubMed]

16. Liu, Q.D.; Mudadu, M.S.; Thummel, R.; Tao, Y.; Wang, S. From blue to red: Syntheses, structures, electronic and electroluminescent properties of tunable luminescent $N, N$ chelate boron complexes. Adv. Funct. Mater. 2005, 15, 143-154. [CrossRef]

17. Liddle, B.J.; Silva, R.M.; Morin, T.J.; Macedo, F.P.; Shukla, R.; Lindeman, S.V.; Gardinier, J.R. BORAZANs: Tunable Fluorophores Based on 2-(Pyrazolyl)aniline Chelates of Diphenylboron. J. Org. Chem. 2007, 72, 5637-5646. [CrossRef] [PubMed]

18. Li, D.; Zhang, H.; Wang, C.; Huang, S.; Guo, J.; Wang, Y. Construction of full-color-tunable and strongly emissive materials by functionalizing a boron-chelate four-ring-fused $\pi$-conjugated core. J. Mater. Chem. 2012, 22, 4319-4328. [CrossRef]

19. Yuan, W.Z.; Chen, S.; Lam, J.W.Y.; Deng, C.; Lu, P.; Sung, H.H.Y.; Williams, I.D.; Kwok, H.S.; Zhang, Y.; Tang, B.Z. Towards high efficiency solid emitters with aggregation-induced emission and electron-transport characteristics. Chem. Commun. 2011, 47, 11216-11218. [CrossRef] [PubMed]

20. Jiang, Y.; Yu, D.; Lu, L.; Zhan, C.; Wu, D.; You, W.; Xie, Z.; Xiao, S. Tuning optical and electronic properties of star-shaped conjugated molecules with enlarged $\pi$-delocalization for organic solar cell application. J. Mater. Chem. A 2013, 1, 8270-8279. [CrossRef]

21. Jin, R.F.; Chang, Y.F. A theoretical study on photophysical properties of triphenylamine-cored molecules with naphthalimide arms and different p-conjugated bridges as organic solar cell materials. Phys. Chem. Chem. Phys. 2015, 17, 2094-2103. [CrossRef] [PubMed]

22. Jin, R.F.; Xiao, W.M. Rational design of organoboron heteroarene derivatives as luminescent and charge transport materials for organic light-emitting diodes. New J. Chem. 2015, 39, 8188-8194. [CrossRef]

23. Liu, Y.; Han, L.; Wang, E.; Xie, M.; Liu, P. Theoretical investigation on charge-tranport properties of pyridine-containing anthracene. J. Mol. Sci. 2014, 30, 46-50.

24. Wen, Z.; Jiang, Y. Ratiometric dual fluorescent receptors for anions under intramolecular charge transfer mechanism. Tetrahedron 2004, 60, 11109-11115. [CrossRef]

25. Huang, W.; Zhang, X.; Ma, L.; Wang, C.; Jiang, Y. Intramolecular charge transfer dual fluorescence of substituted-phenyl p-dimethylaminobenzoates with comparable electron acceptors. Chem. Phys. Lett. 2002, 352, 401-407. [CrossRef]

26. Marcus, R.A. Chemical and electrochemical electron-transfer theory. Annu. Rev. Phys. Chem. 1964, 15, 155-196. [CrossRef]

27. Marcus, R.A. Electron transfer reactions in chemistry. Theory and experiment. Rev. Mod. Phys. 1993, 65, 599-610. [CrossRef]

28. Gruhn, N.E.; da Silva Filho, D.A.; Bill, T.G.; Malagoli, M.; Coropceanu, V.; Kahn, A.; Brédas, J.L. The vibrational reorganization energy in pentacene: Molecular influences on charge transport. J. Am. Chem. Soc. 2002, 124, 7918-7919. [CrossRef] [PubMed]

29. Lin, B.C.; Cheng, C.P.; You, Z.Q.; Hsu, C.P. Charge transport properties of tris(8-hydroxyquinolinato)aluminum(III): Why it is an electron transporter. J. Am. Chem. Soc. 2005, 127, 66-67. [CrossRef] [PubMed]

30. Frisch, M.J.T.; Trucks, G.W.; Schlegel, H.B.; Scuseria, G.E.; Robb, M.A.; Cheeseman, J.R.; Scalmani, G.; Barone, V.; Mennucci, B.; Petersson, G.A.; et al. Gaussian 09; Gaussian, Inc.: Wallingford, CT, USA, 2009.

31. Jin, R. Theoretical study of the optical and charge transport properties of p-conjugated threecoordinate organoboron compounds as organic light-emitting diodes materials. RSC Adv. 2016, 6, 108209-108216. [CrossRef]

32. Suresh, D.; Lopes, P.S.; Ferreira, B.; Figueira, C.A.; Gomes, C.S.B.; Gomes, P.T.; Paolo, R.E.D.; Maçanita, A.L.; Duarte, M.T.; Charas, A.; et al. Tunable fluorophores based on 2-( $N$-arylimino)pyrrolyl chelates of diphenylboron: Synthesis, structure, photophysical characterization, and application in OLEDs. Chem. Eur. J. 2014, 20, 4126-4140. [CrossRef] [PubMed]

33. Lemaur, V.; Steel, M.; Beljonne, D.; Brédas, J.L.; Cornil, J. Photoinduced charge generation and recombination dynamics in model donor/acceptor pairs for organic solar cell applications: A full quantum-chemical treatment. J. Am. Chem. Soc. 2005, 127, 6077-6086. [CrossRef] [PubMed] 
34. Cheung, D.L.; Troisi, A. Theoretical study of the organic photovoltaic electron acceptor PCBM: Morphology, electronic structure, and charge localization. J. Phys. Chem. C 2010, 114, 20479-20488. [CrossRef]

35. Martinelli, N.G.; Idé, J.; Sánchez-Carrera, R.S.; Coropceanu, V.; Brédas, J.L.; Ducasse, L.; Castet, F.; Cornil, J.; Beljonne, D. Influence of structural dynamics on polarization energies in anthracene single crystals. J. Phys. Chem. C 2010, 114, 20678-20685. [CrossRef]

36. McMahon, D.P.; Trois, A. Evaluation of the external reorganization energy of polyacenes. J. Phys. Chem. Lett. 2010, 1, 941-946. [CrossRef]

37. Köse, M.E.; Mitchell, W.J.; Kopidakis, N.; Chang, C.H.; Shaheen, S.E.; Kim, K.; Rumbles, G. Theoretical studies on conjugated phenyl-cored thiophene dendrimers for photovoltaic applications. J. Am. Chem. Soc. 2007, 129, 14257-14270. [CrossRef] [PubMed] 